\title{
Veterinary aspects of rabies
}

\author{
R. V. BLAMIRE \\ M.R.C.V.S., D.V.S.M. \\ Ministry of Agriculture, Fisheries and Food, Tolworth, Surrey
}

\begin{abstract}
Summary
Rabies occurs in domestic animals and wildlife in most parts of the world. Affected mammals invariably die and the disease is greatly feared by man. Control measures can be effective in domestic animals but are difficult to apply in situations where wildlife is affected. Wildlife rabies is spreading southwards in Europe. New legislation has recently been introduced to strengthen the safeguards against importing the disease into Great Britain. Persons should be made aware of this legislation and the dangers of illegally introducing susceptible animals to this country.
\end{abstract}

RABIES is a virus disease which occurs in all mammals. It attacks the central nervous system and, for all practical purposes, is invariably fatal. It is usually transmitted through the bites of animals affected with the disease or at a late stage of incubation. The disease may have a long incubation period-up to 6 months, or even more in exceptional circumstances. It is greatly feared by man because of its inevitable conclusion and because of the terrible sufferings of those who contract the disease.

Rabies is present in most parts of the world except Australasia and Antarctica. It exists in two forms, each of which is interrelated. The first is the classical form of urban rabies which maintains itself within the domestic pet animal population; it is particularly common where large numbers of stray animals are found, for example in the Indian sub-continent and in Latin America. The other form of the disease is present in wildlife and is maintained in the wildlife population with 'spin-offs' into the domestic animal and human populations.

The animals mainly responsible for the spread of urban rabies are, of course, the domestic dog and cat.

\section{Rabies in the British Isles}

Rabies was known in this country for hundreds of years. In the nineteenth century legislation was passed through Parliament which enabled local authories to restrict the movement of dogs, to destroy strays and to require muzzling; later the Board of Agriculture assumed the responsibility for rabies control and the disease appeared to have been eradicated by 1903 (Report, 1971a). We should remember that between 1886 and 1903, 173 human deaths from rabies were recorded in England and Wales. Fortunately the disease did not appear to become established in wildlife.

Great Britain remained free of rabies until 1918, when it reappeared through dogs smuggled into this country, probably by returning servicemen (Report, 1971b). Between 1918 and 1922 the disease was confirmed in 312 dogs, eight cattle, two sheep, three swine and three horses. Severe quarantine measures, combined with restrictions on dogs and destruction of strays, finally overcame the disease in 1922.

From this time until 1969, twenty-five dogs, one leopard and one cat died of rabies in quarantine (Report, 1971c); no case occurred in animals released from quarantine, but in 1966 a case of rabies occurred in a monkey imported 53 days earlier (Boulger, 1966). In 1969 a confirmed case did occur in a dog released from quarantine 10 days before symptoms occurred (Report, 1971d). It is probable that the animal acquired the disease through cross infection in quarantine, as a confirmed case had been reported earlier in the same kennels. Then, early in 1970 (Report, 1971e), another dog developed rabies nearly 3 months after its release from quarantine; there was no evidence whatsoever that the animal could have contracted the disease in quarantine or in this country, and it must be concluded that this was a rare example of a very long incubation period.

These incidents prompted the Secretary of State for Scotland and the Minister of Agriculture, Fisheries and Food to appoint a Committee of Inquiry under Ronald Waterhouse, Q.C., to review the policy and precautions against rabies in Great Britain (Report, 1971). The Committee reported in May 1971 and made a number of recommendations; one of the most far reaching of these was that a very great number of species of mammals previously exempt from quarantine should, in future, be subjected to it. The Committee considered that the 6 months quarantine period which had served the country so well for so many years should be continued, but with greater safeguards, particularly in the design and operation of quarantine premises. 


\section{Urban rabies in other parts of the world}

Urban rabies exists in many parts of the world. It can be controlled by the methods used to eradicate the disease from Great Britain. Its control is now greatly facilitated by the recent development of very effective vaccines. Fig. 1 illustrates the marked decline in urban rabies which has occurred in recent years in the United States. Without 'refreshment' from outside, i.e. from the wildlife cycle, urban rabies can be eliminated, given the will and the resources.

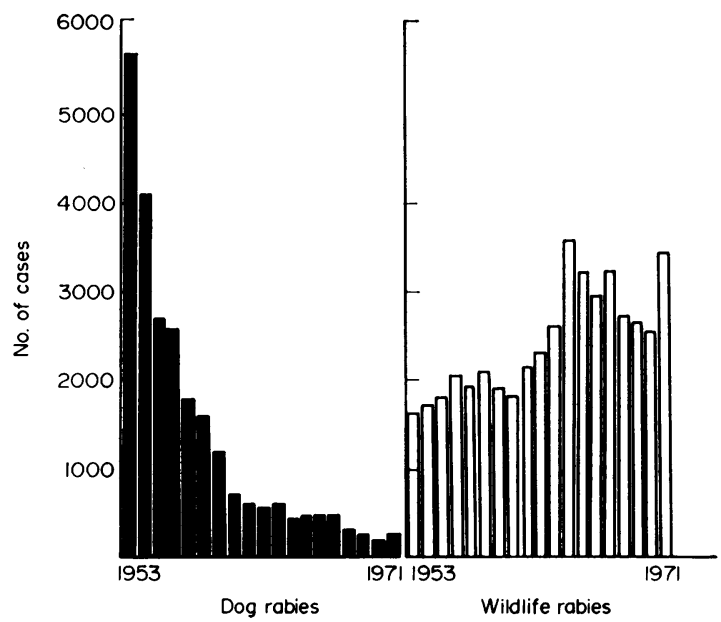

FIG. 1. Rabies in the U.S.A. 1953-1971.

\section{Wildlife rabies}

In different parts of the world, different species of mammals take on the major role of transmitting wildlife rabies. In the Arctic regions and Europe the fox is the main culprit. In the United States the skunk is frequently affected and is known to have passed the disease to humans as well as to other wild animals. It is interesting to note that skunks are popular pets in the U.S.A.; veterinarians are now officially advised not to 'de-scent' these animals because of the risk they present to the public. In Asia and Africa the hyena and jackal are very much involved, while in Mexico and Central and South America the vampire bat is a scourge of the domestic animal population.

\section{Europe}

Over the last 30 or 40 years wildlife rabies has advanced southwards from Poland through Germany and Switzerland and now, steadily, into Northern France. Denmark, Holland and Belgium have remained relatively free, although the disease has made attempts to invade them. The prevalence of rabies in some European countries is shown in Table 1. It can be seen (Table 2) that the number of
TABLE 1. Rabies in 1971 in some European countries

\begin{tabular}{lr}
\hline Country & $\begin{array}{r}\text { No of } \\
\text { cases }\end{array}$ \\
\hline Austria & 225 \\
Belgium & 6 \\
Czechoslovakia & 376 \\
Denmark & Nil \\
France & 883 \\
Germany (East) & 1402 \\
Germany (West) & 1767 \\
Hungary & 552 \\
Italy & 16 \\
Poland & 959 \\
Switzerland & 338 \\
\hline
\end{tabular}

TABLe 2. Rabies in France

\begin{tabular}{cc}
\hline Year & $\begin{array}{c}\text { No. of } \\
\text { cases }\end{array}$ \\
\hline 1967 & Nil \\
1968 & 59 \\
1969 & 334 \\
1970 & 480 \\
$* 1971$ & 883 \\
1972 & 564 (1st 6 months) \\
\hline Including: & \\
240 cattle & 2 solipeds \\
41 cats & 533 foxes \\
22 dogs & 14 badgers \\
13 sheep/goats & 14 other wild \\
2 pigs & \\
&
\end{tabular}

cases in France is steadily increasing, and it is likeli that within a few years the disease will have reacheco the Channel coast. It is interesting to note the numbers and types of domestic animals affected by the disease in Europe it is now a serious cause of cattle mortality.

\section{America}

Wildlife rabies has been extensively studied in the American continents where the disease is responsible for the deaths of almost 300 humans (Report 1972) each year, mostly in Latin America In Canada and the more northern parts of the United States of America the fox, as in Europe, is the main offender. But in the United States as whole the skunk is by far the most frequentl厉 affected. The latest figures available for the United States are for the second quarter of 1972 (Veterinard Public Health Notes, 1972), and 1373 cases of rabies in animals were recorded, the second highest figures since 1958. Seven hundred and fifty skunks were infected, 178 foxes, 117 bats, thirty-four racoons ten mongooses, and five other wild animals; also $\$$ 142 cattle, sixty-two dogs, fifty cats, seventeeno horses and mules, four sheep, two goats and two pigs. 
Further south, from Mexico to the northern part of Argentina, the vampire bat is a menace to livestock (Veterinary Public Health Notes, 1972). The United Nations Food and Agriculture Organization estimate that as a carrier of rabies it is responsible for the death of approximately 1,000,000 head of cattle a year in the Latin American countries, to a total value of $\$ 250$ million. Many methods of control of the vampire bat have been attempted in the past, but with little real success. Research is now being conducted into the possibility of using anti-coagulants to control it and the results are promising. One method involves the injection into the rumen of cattle of anti-coagulant, which is then absorbed into the animals' blood stream. When the bat bites, the anti-coagulant enters the bat's digestive system and, since it consumes its own weight of blood every $24 \mathrm{hr}$, it cannot tolerate the anti-coagulant and dies. Other variations of this approach are being investigated, and there are great hopes that at long last it may be possible to control this dreadful scourge.

\section{Quarantine of imported animals}

Few would contest the need for the quarantine of susceptible animals on importation into this country. Should the disease become endemic here our whole way of life would be changed, and all those farmers, veterinary surgeons, game-keepers, pet-owners and others who come in contact with animals would be exposed to a hazard from which they have been free for many years. No longer would animal bites and scratches need only conservative treatment; all persons so exposed would be liable to undergo the painful process of vaccination with its risk of neurological complications and the fear that vaccination might not be effective.

\section{Quarantine in Great Britain}

\section{Importation of dogs and cats}

Time will allow only a brief description of the procedures which are operated in respect of imported dogs and cats. These are basically the same as those used before the recommendations of the Waterhouse Committee became known, but include certain additional safeguards recommended by the Committee.

A person wishing to import a dog or cat into Great Britain must apply for a licence to the Ministry's Headquarters at Tolworth or the Department of Agriculture's Headquarters in Edinburgh. The person must then make arrangements with a carrier authorized by the Departments who will meet the animal at the place of importation and convey it in strict security to the nominated quarantine premises. There are forty-eight approved quarantine kennels in Great Britain, all of which must be under the control of a veterinary surgeon, who is required to visit daily and to report weekly on the state of animal health to the Divisional Veterinary Officer of the Ministry. All quarantine kennels are approved by the Departments and are inspected every 3 months by a whole-time veterinary officer. There are thirty-three approved carriers, and in addition the veterinary surgeon in charge of kennels may also carry animals if necessary. The heads and necks of all animals which die in quarantine are sent to the Ministry's Veterinary Laboratory at Weybridge, where they are subjected to the fluorescent antibody test, to histological examination and finally to a biological test. No case of rabies has been detected in quarantine since 1969. Performing animals which previously were allowed to perform under supervision during the quarantine period may no longer do so.

All dogs and cats entering quarantine are vaccinated with a dead rabies vaccine on arrival and again 4 weeks later.

The numbers of dog imports into Great Britain during the last 3 years are as follows: 1969, 4023; 1970, 2335 (imports were banned from 13 March to 16 September 1970); 1971, 3533.

The figures for cat imports into Great Britain are: 1969, 1032; 1970, 625; 1971, 1127.

\section{Importation of exotic animals}

Following the recommendations of the Waterhouse Committee new legislation came into effect early this year; The Rabies (Importation of Mammals) Order, 1971. This Order brought within the scope of quarantine many species of animals hitherto exempted. It covers monkeys, rodents, all carnivores and, of course, vampire bats and their offspring for life. The animals scheduled in the Order may only be imported under licence and are subjected to quarantine for 6 months at approved premises, which no longer include travelling circuses. The animals may only be landed at designated ports or airports. They must be transported by authorized carriers, in suitable containers and vehicles, to the approved quarantine premises; a carrier or his employee must accompany the animals if they are transported by rail. Research establishments approved for quarantine must be under the general supervision of an authorized veterinary surgeon or registered medical practitioner, who will have overals responsibility for the safe custody and isolation of the animals during the period of detention.

A major factor in enforcing this Order has been that a wide range of imported laboratory animals now come within the scope of the quarantine legislation. The additional work load may be judged by a study of the following figures for imports for the first 6 months of 1972: (a) monkeys, 5400; (b) rodents, 19,000 rats, 47,000 mice, 1986 guinea-pigs; 
(c) miscellaneous animals, including 2000 mink, thirty-eight bats, twenty-six shrews, four lemmings, and others.

We are very conscious of the additional burden which these requirements put upon the research departments having responsibility for the safety of these animals. We have tried within the terms of the Order, and consistent with the maintenance of security, to reduce to a minimum any interference with the normal business of research premises.

In addition to these large numbers of animals which are genuinely imported, an enormous transshipment trade in scheduled animals takes place, particularly through London Airport.

\section{Illegal importations}

Over the past year there have been 213 unlicensed landings known to the Department. Thirteen prosecutions have been notified to us and an average fine of $£ 30$ was imposed. The maximum possible fine for such offences is $£ 400$.

Most of these unlicensed landings were contraventions of the licensing requirements through ignorance of the proper procedures. Because of the inadequacy of facilities for holding animals at most ports and airports, even openly declared animals which have not been properly licensed can create considerable difficulties for Customs, the portal authorities and other Departments. But a minority of such landings are wilful attempts to evade quarantine, and where such evasions are successful they pose the greatest threat we have of the introduction of the disease to this country. The number of successful evasions is, of course, unknownz Nevertheless, any one smuggled animal could b enough to import the disease, and the risks are likely to grow rather than diminish. It is importan that the public should not be allowed to forget the reasons for quarantine, and both the veterinary an medical professions must play their part in main taining this state of alertness.

\section{Acknowledgments}

I should like to thank my colleague $\mathrm{Mr} \mathrm{M}$. Macaulay $\overrightarrow{0}$ M.R.C.V.S., for his help in the preparation of this paper.

\section{References}

Boulger, L.R. (1966) Natural rabies in a laborator monkey. Lancet, i, 941.

REPORT (1971) Report of the Committee of Inquiry onf Rabies. Cmnd. 4696.

REPORT (1971a) Report of the Committee of Inquiry on Rabies. Cmnd. 4696, 2. 5.

REPORT (1971b) Report of the Committee of Inquiry of Rabies. Cmnd. 4696, 2. 11.

REPORT (1971c) Report of the Committee of Inquiry of Rabies. Cmnd. 4696, Appendix C.

REPORT (1971d) Report of the Committee of Inquiry or Rabies. Cmnd. 4696, 2. 13.

REPORT (1971e) Report of the Committee of Inquiry of Rabies. Cmnd. 4696, 2. 17.

RePORT (1972) Pan-American Zoonoses Center-Epidenôfo logical Rabies Surveillance for the Americas. Reprif July 1969-June 1972. Centro-Panamericano de Zoonoses Casilla de corru 23. Ranios mejia. Prov. de Buenos Aiłes Argentina.

Veterinary Public Health Notes (1972) National Comō municable Disease Center, July 1972. Center for Disease Control, Atlanta, Georgia 30333, U.S.A. 